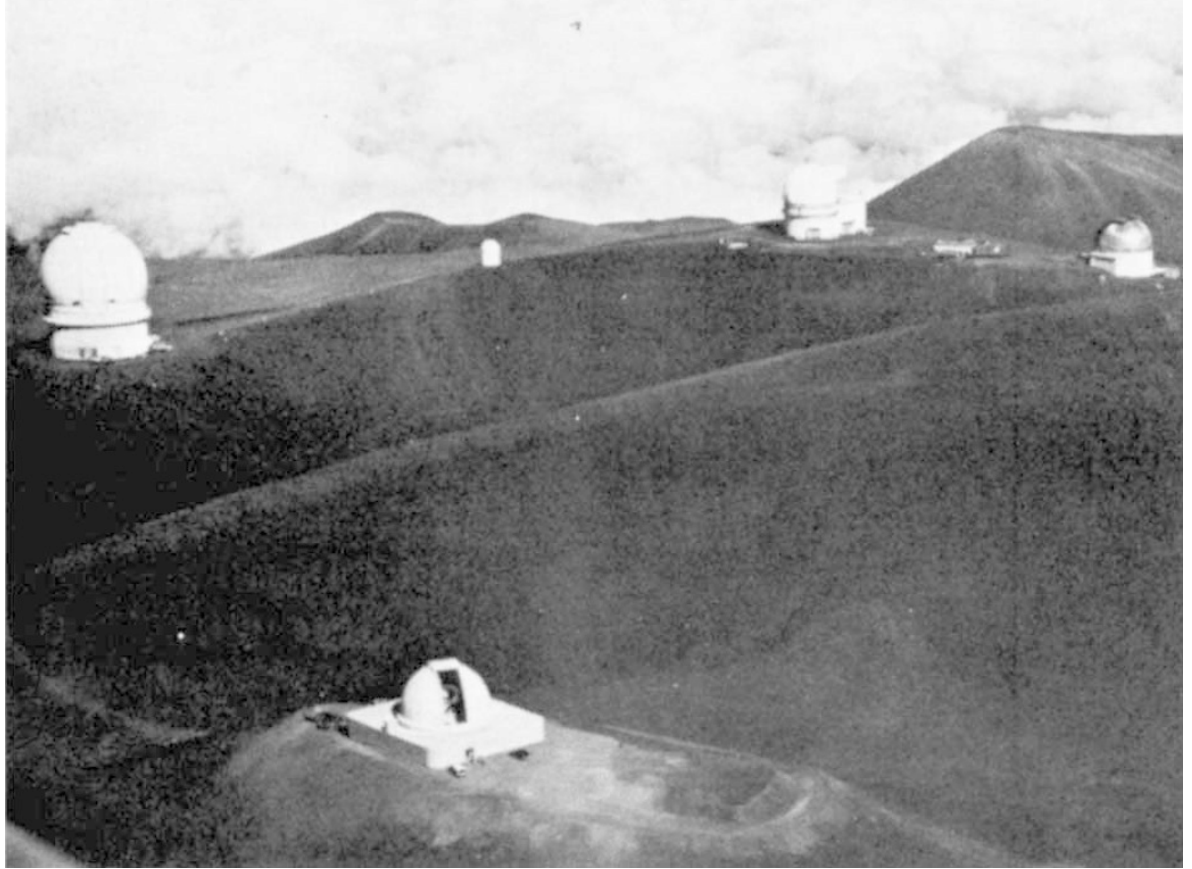

On top of Mauna Kea: In the foreground is the NASA infrared telescope; on the ridge (left to right) the Canada-France-Hawaii telescope, the $2.2 m$ Hawail telescope, and the latest arrival, UKIRT

\title{
Britain joins Hawaii summit
}

THE United Kingdom Infrared Telescope (UKIRT) at the summit of Mauna Kea on the island of Hawaii was opened by HRH the Duke of Gloucester on 10 October. Funded by the Science Research Council and operated by the Royal Observatory, Edinburgh, this 3.8-m diameter instrument is the largest telescope in the world designed specifically for infrared observations.

The UKIRT, however, is not the only telescope to have been built recently on Mauna Kea. The NASA $3 \mathrm{~m}$ Infared Telescope Facility, and the $3.6 \mathrm{~m}$ CanadaFrance-Hawaii Telescope have also opened within the past three months, joining three smaller University of Hawaii telescopes already on the summit. In terms of collecting area, Mauna Kea now houses the world's largest observatory for optical and infrared astronomy.

Infrared astronomers will be looking with particular interest at the relative performance of the UKIRT and NASA telescopes, since their design philosophies are significantly different. The British instrument goes for maximum collecting area while in the NASA telescope, which cost about twice as much as the UKIRT, image quality and guiding stability are given the highest priority. The CanadaFrance-Hawaii telescope and the University of Hawaii 2.2-m telescope are also instrumented for infrared observations.

The UKIRT telescope cost $£ 2.7 \mathrm{~m}$ and was built by the Sheffield company of Dunford Hadfields, Ltd, using a Cer-Vit primary mirror which was ground and polished by Grubb Parsons, Ltd, of
Newcastle. An important feature of the design of the telescope is the thinness of its mirror, which weighs only $40 \%$ of that of a conventional telescope of the same aperture. As a result, the whole instrument was built at very substantial saving of weight and cost as compared with, for example, the similar sized AngloAustralian Telescope. The lightweight structure has the disadvantage of lesser rigidity, but careful design and the use of computer controlled pointing has resulted in an instrument whose performance approaches that of the best optical telescopes.

The instrumentation for the telescope, built in Edinburgh, includes photometers and low resolution spectrometers covering the wavelength range $1-40 \mu \mathrm{m}$. The detectors in use are cryogenically cooled solid state devices such as indium antimonide photovoltaic detectors or gallium-doped germanium bolometers. Stray thermal infrared emission from the sky and from the telescope itself is a major problem in infrared astronomy; the optical system has therefore been designed to minimise the size and effective emissivity of the mechanical and optical components that lie in the telescope beam. In order to separate the signal due to a celestial infrared source from the background emission the secondary mirror itself oscillates at up to $40 \mathrm{~Hz}$, providing the detector with near-simultaneous images of two adjacent areas of sky.

Gareth Wynn-Williams

Gareth Wynn-Williams is Associate Professor of Astronomy at the University of Hawaii

\section{Coast guards probe mystery of missing research ship}

WITHIN the next few weeks, the US coast guard hope to have developed a plausible explanation for the mysterious disappearance last December of a research vessel charted by the University of Hawaii with seven scientists on board.

No trace of the vessel, the Holoholo, has been found since it set sail from Honolulu harbour on the afternoon of 9 December. The trip was one of a series planned to gather data on the oceanographic conditions off the Hawaii coast in connection with the siting of a proposed ocean thermal energy conversion (OTEC) project supported by the Department of Energy.

Evidence has been found to indicate that the vessel may have put in to shore to make bench-mark readings for some of the scientific equipment. However, the alarm was raised when it failed to make a planned rendezvous with two scientists two days after its departure from Honolulu, following a period of stormy weather.

On board the Holoholo at the time of its disappearance were three scientists from the University of Hawaii - including the principal investigator for the project, assistant professor of engineering Dr Gary C Niemeyer - two scientists from the University of California's Lawrence Livermore Laboratory, which has responsibility for the OTEC research programme, and two scientists from the National Oceanographic and Atmospheric Agency.

Various theories about the disappearance have been voiced during extensive hearings that have already been held in Honolulu by a board of enquiry established jointly by the coast guard and the National Transportation Safety Board. These range form the hypothesis of an explosion on board to the suggestion by some, quoting the Glomar Explorer's links with the CIA, that the vessel might have been captured by a foreign power.

According to a local newspaper, the Honolulu advertiser, the board that the boat sank after being swamped by heavy seas - and that the swamping may have been partly due to structural alterations made to the vessel to accommodate various species of equipment required for the research.

The safety board has already issued a set of recommendations to the University following the Holoholo's disappearance in which it says that some of the alterations, which included the installation of two large winches, a large spool of cable, and an A-frame cargo boom on the after part of the vessel, "may have adversely affected the 
seaworthiness of the vessel".

The board points out, for example, that although the chief scientist principal scientist was "a highly regarded investigator with considerable knowledge and experience in ocean research", there was no evidence that he or the other scientists had expertise in vessel seaworthiness, stability, or navigation.

The board also raises questions with regard to the adequacy of procedures adopted by the university for observing guideline safety standards for research vessels laid down in may 1976 by the University National Oceanographic Laboratory System (UNOLS), based at Woods Hole in Massachusetts, an Association of Oceanographic Institutions.

\section{Drought could turn Dead Sea into a desert}

Crossing the Dead Sea on foot is now theoretically possible - if it weren't for the presence of border patrols - according to Shlomo Drori, a leading Israeli expert on the use of Dead Sea resources. Following the worst drought in the history of the State of Israel, the sea has split in two at its narrowest point.

The Dead Sea's sole feeder is the lower Jordan, which is becoming increasingly depleted by water developments, both Israeli and Jordanian. Last November, even before the onset of the drought, Yigal Allon, the former Israeli foreign minister spoke in the Knesset of the "urgent" problem of the Dead Sea. Current Jordanian water projects involve the damming of all eastern tributaries of the Jordan; when these are completed, said $\mathrm{Mr}$ Allon, the lower Jordan would totally disappear save as a drainage channel, the Dead Sea level would fall signifacantly, and the southern part of it would become a salt desert. This, as the Energy Minister Yitzak Moda'i admitted in his reply to $\mathrm{Mr}$ Allon, could cause "tremendous" and possibly irreversible ecological damage.

It is, however, Israel's water schemes which are the main consumers of sources which would, without human intervention, end up in the Dead Sea. For the lower Jordan flows from the sea of Galilee, which, via the National Aquifer, serves as the water source of the whole country. According to Professor Yoram Avnimelech, a soil chemist seconded from the Technion to the Sea of Galilee Conservancy Board, considerable problems are posed to conservationists by the unique status of the Sea of Galilee, including its religious and historical associations. The normal way of treating a
It points out that although these include "an excellent array of standards and procedures which would be applicable to most research vessel operations", and despite the fact the University of Hawaii is member of UNOLS, the guideline standards had not been applied to the Holoholo, which was not owned by the university but had been commissioned through a subcontract with the university's research corporation.

As a result, says the board, the operation of the Holoholo apparently relied on the charter contractor for vessel seaworthiness, on the contract with the boat's master - of whom there is no evidence or expertise in vessel stability for safe operation, and on the judgement of the chief scientist as to the suitability of the vessel to serve as a platform for the research projects to be conducted.

"There is no evidence that any of the guidelines standards were considered or applied by three individuals involved or by any other officials of the university or research corporation" the board says.

Officials at the university, which may be sued for substantial damages by the relatives of those on board the vessel when it disappeared, have declined so far to make any public statement about the incident, apart from saying that the specific recommendations of the safety board to prevent similar occurences in the future" are now under study by university officials.

David Dickson

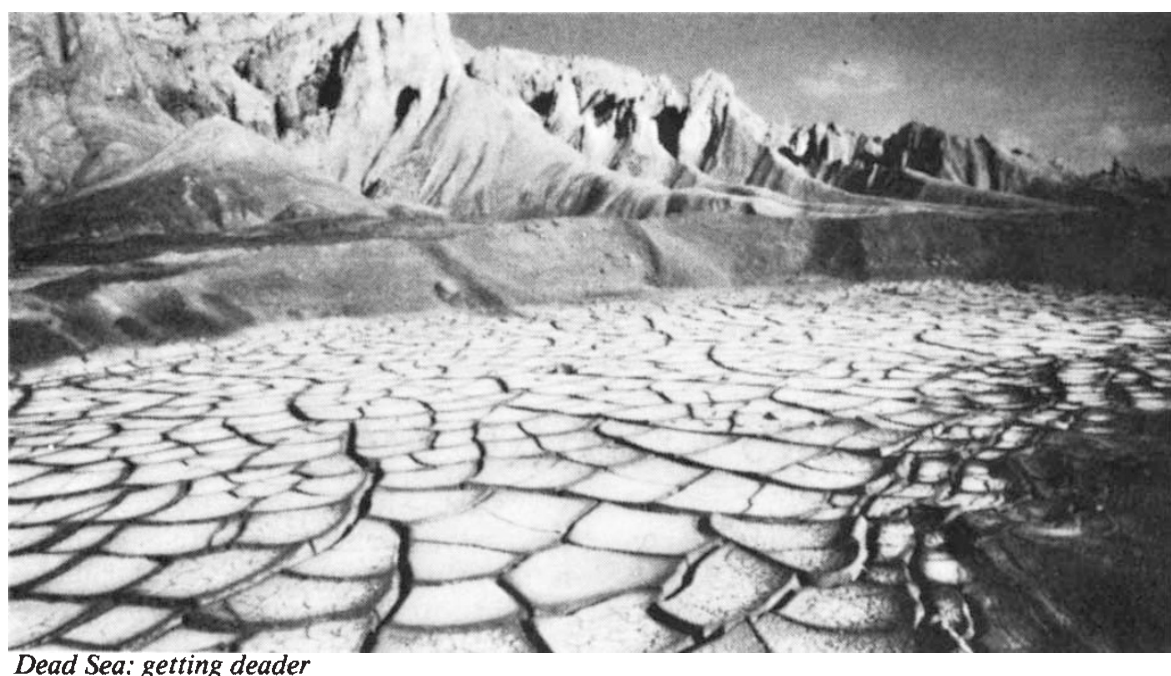

lake scheduled as a drinking water source, he told Nature, is to fence it off, minimise development of the watershed, and try to keep the population out. This, however, is not possible in Israel, which has a limited supply of water - indeed, in the summer, every drop of water from the springs of the Upper Galilee is used three times by irrigation and fish-farming schemes before it even reaches the Sea of Galilee.

On occasion, the needs of the Conservancy seem to run counter to Israeli national sentiment. In 1968, workers at the Limnological Laboratory at Tevhag began to observe excessive levels of nitrates in the water, due not only to the use of fertilisers in the Upper Galilee but also to the uncovering of the organic soils of the Huleh valley. Since the reclamation of the Huleh marshes has attained a saga-like status in Israeli history, the obvious alternative of reflooding the Huleh was simply not acceptable, but it took several years of intensive research before a suitable strategy was devised to obviate the danger of eutrophication posed by the excess nitrates. (This is based, incidentally, on short-term sprinkling of the Huleh soil at high summer temperatures to encourage the action of denitrifying bacteria).

Professor Avnimelech, who is very much the scientific trouble-shooter for the Sea of Galilee Conservancy, also indicated another area where Jewish sentiments and the needs of conservation may yet clash. "Planting a tree in Israel" is a tradition with considerable emotional overtones to Israeli and Diaspora Jews alike - yet recent indications, Professor Avnimelech said, suggest that over-zealous treeplanting in the Galilee watershed may be causing environmental deterioration.

Yet, however well the Water Conservancy Board husbands the Galilee resources in times of drought, the Sea of Galilee itself may be at risk. This summer, the water level fell dangerously low, and when the rain finally fell just before Jewish New Year, one official revealed that no water had been taken from the Sea of Galilee for almost four months - the country had been subsisting solely from supplies stored in auxiliary reservoirs along the aquifer.

As far as the depleted - and now divided - Dead Sea is concerned, there does exist one fairly obvious means of replacing the waters lost to human needs. This is the construction of a canal to bring in water from the Mediterranean. Israel, of course, does not have the funds to contemplate such a scheme merely as an ecological rescue operation. However, the Dead Sea lies some $400 \mathrm{~m}$ below the level of the Mediterranean, so that, the canal could descend via series of hydroelectrical cascades which could according to current calculations, produce up to $10 \%$ of Israel's 